\title{
Bilateral double parotid ducts: a case report*
}

\author{
Hülya Üçerler, Z. Aslı Aktan İkiz, Fatme Soylu, Narmin Farajiband, Mustafa Deniz Yörük, Pınar Çă̆ımnı \\ Department of Anatomy, School of Medicine, Ege University, Izmir, Turkey
}

\begin{abstract}
The parotid duct is formed by the confluence of two ducts in the gland which ascend and descend at right angle to the main duct. While crossing the masseter muscle, it can receive the accessory parotid duct. Although the anatomical course of this duct is well known, the reports on its normal anatomical variations and morphometry are very few. During routine dissection in the Department of Anatomy of Ege University School of Medicine, double parotid ducts were observed bilaterally in a 72-year-old male cadaver. These were traced carefully and neighboring anatomic structures were demonstrated. The two ducts on both sides merged with each other to form the main parotid duct that had a straight course running horizontally towards the anterior border of the masseter muscle. The length of the main parotid duct was $20.02 \mathrm{~mm}$ on the right side and $16 \mathrm{~mm}$ on the left side. The distance between tragus and the union point of the double ducts was $52 \mathrm{~mm}$ on the right side and $58.72 \mathrm{~mm}$ on the left side. Detailed morphometry and location of the double parotid ducts are useful for diagnostic and therapeutic luminal procedures.
\end{abstract}

Keywords: double parotid duct; parotid duct; parotid gland; sialography; Stensen's duct

Anatomy 2016;10(3):239-241 @2016 Turkish Society of Anatomy and Clinical Anatomy (TSACA)

\section{Introduction}

The parotid gland is the largest salivary gland in the human projecting forwards on the surface of masseter muscle. In $20 \%$ of cases, the accessory parotid gland lies between the zygomatic arch above and the parotid duct below. Small ducts from the accessory gland drain into the parotid duct. ${ }^{[1-3]}$

The parotid duct, also known as the Stensen's duct after the Danish neuroanatomist Neils Stensen, begins with the confluence of two main tributaries within the anterior part of the gland. It appears at the anterior border of the upper part of the parotid gland and passes across the masseter. The parotid duct turns medially to reach the oral cavity at the anterior border of the muscle. A single duct usually drains the parotid gland. ${ }^{[1,46]}$ This duct is formed by the confluence of the two ducts in the gland which ascend and descend at a right angle to the main duct. ${ }^{[4]}$ It can receive the accessory parotid duct while crossing the masseter. ${ }^{[1]}$ The lumen of the parotid duct is about 3 to $4 \mathrm{~mm}$ in diameter and its length is about $5 \mathrm{~cm}^{[1,3,3]}$
Although the anatomical course of this duct is well known, the reports on its normal anatomical variants and morphometry are very few. ${ }^{[7]}$ Understanding the variations of the parotid duct is important for the assessment new diagnostic and therapeutic techniques. ${ }^{[7]}$ Besides, the proper knowledge of the normal topographic anatomy and variations of the parotid duct provides easy understanding of the analysis of radiographic images and computerized tomographic scans used in sialography. ${ }^{[3]}$ The aim of current study was to report a rare anomaly of the parotid duct because of its clinical importance for both diagnostic and therapeutic procedures.

\section{Case Report}

During routine dissection in the Department of Anatomy, Ege University School of Medicine, bilateral double parotid ducts were observed in a formalin-fixed 72-yearold male cadaver. The cadaver had no trace of scars, adhesions or signs of trauma or operation. All measurements were taken using a stainless steel caliper with an accuracy of $0.02 \mathrm{~mm}$. The study conforms to the provisions of the Helsinki Declaration of 1964 and all subsequent revisions.

*This study has been presented as a poster at the XXIV International Symposium on Morphological Sciences (ISMS) in Istanbul, Turkey in 2015. 
Parotid ducts on both sides were traced carefully and neighboring anatomical structures were demonstrated. The two ducts on both sides merged with each other and formed the main parotid duct. The duct then had a straight course and ran horizontally towards the anterior border of the masseter (Figures 1 and 2). Diameters were measured from the anterior border of the masseter muscle on both sides (Tables $\mathbf{1}$ and $\mathbf{2}$ ).

\section{Discussion}

There are few studies on the surface anatomy of the parotid duct based on cadaver dissections and analyzing sialograms. ${ }^{[5]}$ The duplication of the parotid duct as a previously unreported anomaly was observed in the dissection laboratory of Ege University School of Medicine by Aktan et al. (2001). ${ }^{[4]}$ This was a unilateral anomaly, on the right side. The fusion of the upper and lower ducts was outside the gland $4.8 \mathrm{~cm}$ beyond their emergence from it. They pierced the buccinator as a single duct. The distance from the union point to the buccinator muscle was $0.7 \mathrm{~cm}$.

Stringer et al. ${ }^{[5]}$ scanned fifty healthy adults using ultrasound to redefine the surface anatomy of the parotid duct. The duct was on the middle half line between the lower border of the tragus and the cheilion in more than $90 \%$ of the individuals. The lower duct was in this region

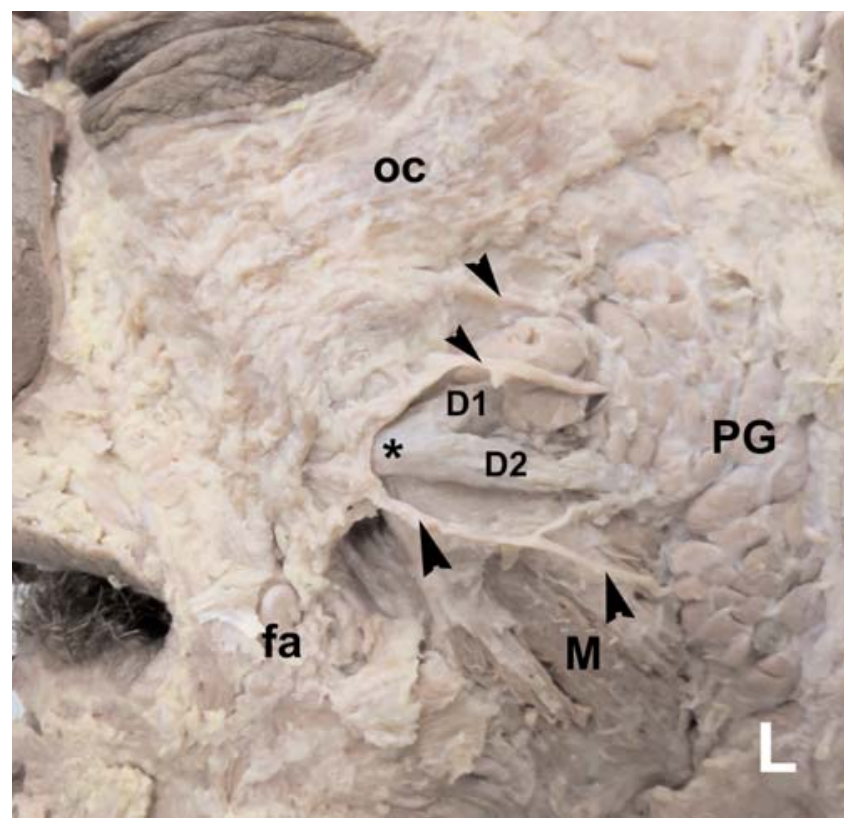

Figure 1. Double parotid ducts (left side). D1: upper parotid duct; D2: lower parotid duct; fa: facial artery; M: masseter muscle; oc: orbicularis oculi muscle; PG: parotid gland, *main parotid duct, arrowheads: facial nerve. [Color figure can be viewed in the online issue, which is available at www.anatomy.org.tr]
Table 1

Double parotid duct measurements on the right and left sides.

\begin{tabular}{lcccc}
\hline & $\begin{array}{c}\text { Upper } \\
\text { duct } \\
\text { Right } \\
(\mathbf{m m})\end{array}$ & $\begin{array}{c}\text { Lower } \\
\text { duct } \\
\text { Right } \\
(\mathbf{m m})\end{array}$ & $\begin{array}{c}\text { Upper } \\
\text { duct } \\
\text { Left } \\
(\mathbf{m m})\end{array}$ & $\begin{array}{c}\text { Lower } \\
\text { duct } \\
\text { Left } \\
(\mathbf{m m})\end{array}$ \\
\hline Length & 12.14 & 20.82 & 10 & 27.3 \\
\hline Diameter & 5.52 & 5.6 & 5.98 & 5.34 \\
\hline $\begin{array}{l}\text { Distance between tragus } \\
\text { and emergence point }\end{array}$ & 46.2 & 36.9 & 47.98 & 36.8 \\
\hline $\begin{array}{l}\text { Distance between } \\
\text { zygomatic arch and duct }\end{array}$ & 21.94 & 27.2 & 22.74 & 29.3 \\
\hline
\end{tabular}

Table 2

Measurements of the main parotid duct after fusion of the two ducts on the right and left sides.

\begin{tabular}{lcc}
\hline & Right (mm) & Left (mm) \\
\hline $\begin{array}{l}\text { Distance between lower border of tragus and } \\
\text { center of philtrum }\end{array}$ & 134.5 & 129.34 \\
\hline $\begin{array}{l}\text { Distance between lower border of tragus and } \\
\text { labial commissure }\end{array}$ & 96.74 & 98.64 \\
\hline Length (union point-buccinator piercing) & 20.02 & 16 \\
\hline $\begin{array}{l}\text { Distance between lower border of tragus and } \\
\text { union point of double ducts }\end{array}$ & 52 & 58.72 \\
\hline
\end{tabular}

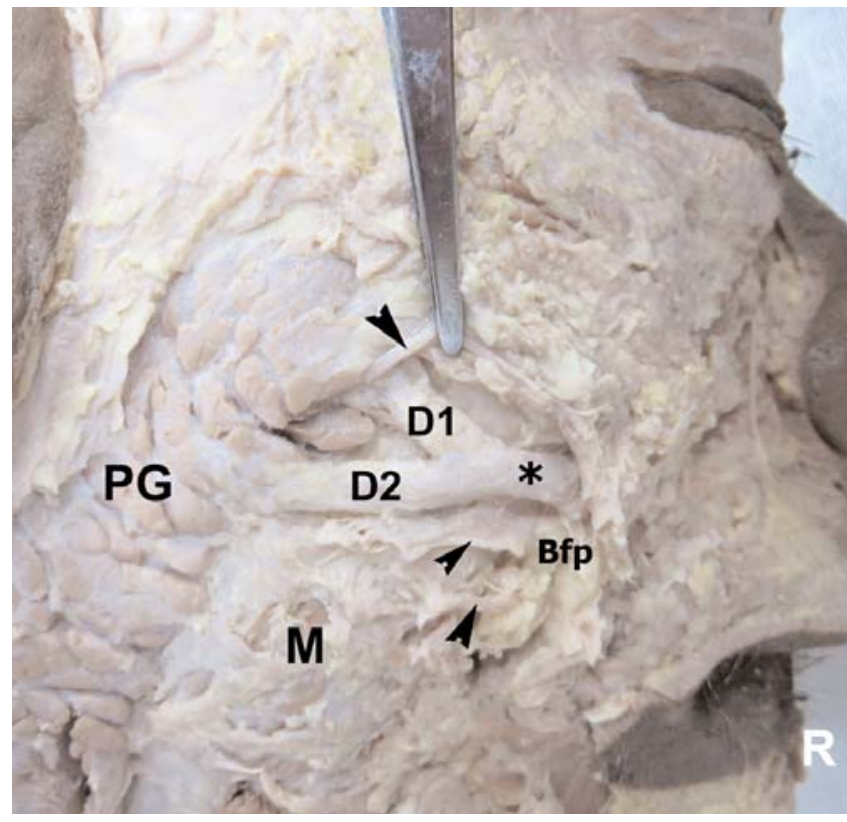

Figure 2. Double parotid ducts (right side). Bfp: buccal fat pad; D1: upper parotid duct; D2: lower parotid duct; M: masseter muscle; PG: parotid gland; *main parotid duct; arrowheads: facial nerve. [Color figure can be viewed in the online issue, which is available at www.anatomy.org.tr] 
in our cadaver also; the upper duct was not crossing, but over this line. Fernandes et al. ${ }^{[3]}$ also reported this rare variation of the parotid duct during a dissection on the right side in a 46-year-old male cadaver. The lengths of the superior and inferior ducts were $26.49 \mathrm{~mm}$ and 37.25 $\mathrm{mm}$, respectively.

The presence of double parotid ducts can be explained on the basis of development of the parotid gland. The parotid gland arises from the epithelial lining the primitive oral epithelium as an elongated furrow, spreading back towards the ear. It can be recognized in human embryos about $8 \mathrm{~mm}$ long, at the sixth week of gestational age. It runs between the mandibular and maxillary prominences, and then converts into a tube and loses its connection with the epithelium of the mouth except its ventral end. It grows dorsally and invaginates into the adjacent mesenchyme in the cheek region. The tube persists as the parotid duct and its blinded end sprouts to several epithelial branches that proliferate to form secretory portion (acini) of the gland at the tenth week of gestational week. ${ }^{[1,4]}$ In cases with double parotid ducts, the epithelial sprout was bifurcated and each branch invaginated into the adjacent mesenchyme separately. These branches made two variant ducts. ${ }^{[8]}$ Astik and Dave ${ }^{[2]}$ reported double parotid ducts bilaterally in a 50-year-old male cadaver in 2011 during routine dissection. They reported that the cell-matrix interactions and growth factors had importance on morphogenesis and cyto-differentiation of the parotid gland and development of this variation.

The knowledge of the actual dimensions of the excretory ducts is important in duct endoscopy and lithotripsy. This variation also has clinical importance for parotid gland suegery and facial cosmetic surgeries. ${ }^{[2]}$ In CT sialography and CT fistulography, double parotid ducts may be a confused with congenital fistula from accessory parotid gland. Additionally, the duct may be severed by a facial laceration and is at risk of iatrogenic injury during facial surgery and injection of botulinum toxin into masseter muscle, because of its superficial location. ${ }^{[5]}$ To keep in mind the double parotid duct variation will reduce iatrogenic injury risks and improve diagnosis of parotid duct injury.

\section{References}

1. Standring $S$ (editor). Gray's anatomy: the anatomical basis of clinical practice. 29th ed. Edinburgh (Scotland): Elsevier Churchill Livingstone; 2005. p. 515-7.

2. Astrk RB, Dave UH. Embryological basis of bilateral double parotid ducts: a rare anatomical variation. International Journal of Anatomical Variations 2011;4:141-3.

3. Fernandes ACS, Lima RG, Rossi MA, Aguiar MC. Parotid gland with double duct: an anatomic variation description. Int J Morphol 2009;27:129-32

4. Aktan ZA, Bilge O, Pinar YA, Ikiz AO. Duplication of the parotid duct: a previously unreported anomaly. Surg Radiol Anat 2001;23: 353-4.

5. Stringer MD, Mirjalili SA, Meredith SJ, Muirhead JC. Redefining the surface anatomy of the parotid duct: an in vivo ultrasound study. Plast Reconstr Surg 2012;130:1032-7.

6. Perrini P, Lanzino G, Parenti GF. Niels Stensen (1638-1686): scientist, neuroanatomist, and saint. Neurosurgery 2010;67:3-9.

7. Horsburgh A, Massoud TF. The salivary ducts of Wharton and Stenson: analysis of normal variant sialographic morphometry and a historical review. Ann Anat 2013;195:238-42.

8. Hassanzadeh Taheri MM, Afshar M, Zardast M. Unilateral duplication of the parotid duct, its embryological basis and clinical significance: a rare cadaveric case report. Anat Sci Int 2015;90:197-200.

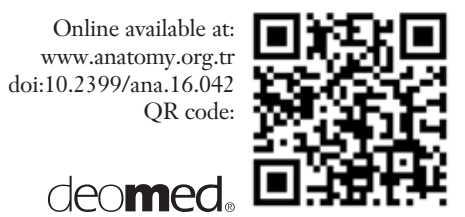

Correspondence to: Hülya Üçerler, MD

Department of Anatomy, Ege University, School of Medicine, Bornova, Izmir, Turkey

Phone: +9023239039 93

e-mail: hulyaucerler@gmail.com, hulya.ucerler@ege.edu.tr

Conflict of interest statement: No conflicts declared.

This is an open access article distributed under the terms of the Creative Commons Attribution-NonCommercial-NoDerivs 3.0 Unported (CC BY-NCND3.0) Licence (http://creativecommons.org/licenses/by-nc-nd/3.0/) which permits unrestricted noncommercial use, distribution, and reproduction in any medium, provided the original work is properly cited. Please cite this article as: Üçerler, H, Aktan İkiz ZA, Soylu F, Farajiband N, Yörük MD, Çağımnı P. Bilateral double parotid ducts: a case report. Anatomy 2016;10(3):239-241. 